\title{
Hoechst 33342 stain and u.v. laser exposure do not induce genotoxic effects in flow-sorted boar spermatozoa
}

\author{
I Parrilla, J M Vázquez, C Cuello, M A Gil, J Roca, D Di Berardino and E A Martínez \\ Department of Animal Medicine and Surgery, University of Murcia, 30071 Murcia, Spain and ${ }^{1}$ Department of \\ Animal Science and Food Inspection, University of Naples 'Federico II', 80055 Portici, Naples, Italy
}

Correspondence should be addressed to I Parrilla; Email: parrilla@um.es

\begin{abstract}
Sex selection by flow cytometry/cell sorting involves the staining of spermatozoa with Hoechst 33342 in combination with the impact of a u.v. laser beam, two potentially mutagenic agents. A phenotypic and cytogenetic study of lymphocytes of piglets born after insemination with spermatozoa stained with Hoechst 33342 and from piglets obtained from stain-sorted spermatozoa was performed to evaluate the genotoxic effect of Hoechst 33342 staining and u.v. laser irradiation on the offspring. Lymphocytes from piglets born after insemination with unstained spermatozoa, but from the same ejaculate, were used as a control group. Peripheral blood lymphocytes from these piglets were cultured following a standard cell culture protocol. Cells were then collected by centrifugation, subjected to hypotonic solution and fixed and dropped onto slides. Sister chromatid exchanges (SCEs) and chromosome aberrations (CAs: including chromosome and chromatid breaks) per cell were scored in 50-s division metaphase spreads from each donor. Reproductive parameters and litter performance of all inseminations performed were also recorded in all groups. Data were analyzed by ANOVA. No significant increase $(P>0.05)$ of SCE and CA frequencies were observed in piglets born from stained spermatozoa or from stain-sorted spermatozoa with respect to controls (untreated sperm). The results indicated that no mutagenic effect on spermatozoa, expressed as increases in the incidence of abnormalities in the resulting offspring and also as increases in SCE and CA frequencies on lymphocytes from these individuals, was induced by the staining of boar spermatozoa with Hoechst 33342, nor by combination of staining with laser impact during flow cytometry.

Reproduction (2004) 128 615-621
\end{abstract}

\section{Introduction}

Flow cytometrically sorted $X$ and $Y$ chromosome-bearing spermatozoa have been successfully used to obtain offspring in domestic animals and humans using several assisted reproductive technologies (reviewed by Johnson 2000). Flow cytometric sorting is widely accepted as a safe technique in practice, in the absence of phenotypic evidence that suggests otherwise. As far as we know, the only disadvantageous effects described when flow-sorted spermatozoa are used for insemination are the short fertile life span of the spermatozoa as well as the loss of embryos during gestation, expressed as a reduced litter size in both rabbits (Johnson et al. 1989) and pigs (Johnson 1991, Vazquez et al. 2003). However, the reason for this reduction remains unclear.

It is well known that Hoechst 33342 could have toxic and mutagenic effects upon certain cell types (Durand \& Olive 1982), and also that u.v. light produces an increase in chromosome structural abnormalities in mouse spermatozoa (Matsuda \& Tobari 1988). Concerns have been raised that simultaneous use of both agents may affect the genetic safety of sperm selection by flow cytometry (Ashwood-Smith 1994, Munné 1994, Gardiner-Garden 1999) and, consequently, the necessity to evaluate DNA damage on the sorted spermatozoa has become a priority in spite of the absence of congenital abnormalities (Morrel \& Dresser 1989). However, no cytogenetic studies on the potentially mutagenic effect of flow cytometric-sorting technology on the animals born after insemination with spermatozoa processed with this technology have been reported.

Evaluation of the increases in baseline frequencies of cytogenetic endpoints such as sister chromatid exchanges (SCEs) and chromosome aberrations (CAs) has been used for many years to measure the possible mutagenic and carcinogenic effect when cells, animal or human, are exposed to known genotoxic agents (Perry \& Evans 1975, Latt et al. 1981, Albertini et al. 2000).

While it has been determined that SCE is an ideal method for evaluating the genotoxic potential of those 
substances that induce DNA damage or interfere with DNA metabolism or repair, CA has been more related with those substances that directly break the backbone of DNA or significantly distort the DNA helix (Carrano \& Natarajan 1988).

Consequently, the cytogenetic analysis using SCE and CA of animals born after insemination with spermatozoa stained with Hoechst 33342 and/or flow cytometrically sorted could represent an ideal means of determining the safety of this sex selection procedure.

The aim of the present study was to evaluate the phenotypic and cytogenetic normalcy of piglets born after insemination with Hoechst 33342-stained spermatozoa or stained and flow cytometrically sorted boar spermatozoa.

\section{Materials and Methods}

All reagents used in this study were provided by SigmaAldrich Co. (Alcobendas, Madrid, Spain), unless otherwise stated.

\section{Animals}

All animal experiments were approved by the ethical committee for animal experiments of the University of Murcia, Spain.

Animals were obtained from a commercial pig farm in Murcia (Spain). All males and females used for artificial insemination $(\mathrm{Al})$ were sexually mature crossbred pigs. Sows (parity of two to six) were selected on the day of weaning and allocated individually to crates in a mechanically ventilated confinement facility. Mature boars of proven fertility were housed in individual pens in a controlled environment $\left(23 \pm 2{ }^{\circ} \mathrm{C}\right)$. Animals received a commercial diet according to their reproductive condition, water being available ad libitum. Piglets generated from matings between these breeding animals were allocated into groups in a mechanically ventilated confinement facility and fed with a commercial ration twice a day, water being available ad libitum.

\section{Semen collection and processing}

Sperm-rich ejaculate fractions were obtained from five boars using the gloved-hand method, pooled and extended in Beltsville thawing solution (BTS; $205.0 \mathrm{mmol}$ glucose, $20.39 \mathrm{mmol} \mathrm{NaCl}, 5.4 \mathrm{mmol} \mathrm{KCl}, 15.01 \mathrm{mmol}$ $\mathrm{NaHCO}_{3}$ and $3.35 \mathrm{mmol}$ EDTA (Johnson et al. 1988)) to $30 \times 10^{6}$ spermatozoa $/ \mathrm{ml}$. Shortly after collection, the semen samples were evaluated and used if they met the minimum criteria: motility $>80 \%$, viability $>85 \%$, acrosomal abnormalities $<10 \%$, abnormal sperm morphology $<15 \%$ (Vazquez et al. 1997).

Spermatozoa were prepared using the Beltsville sperm sorting technology protocol as adapted for high speed sorting (Johnson \& Welch 1999) except that all spermatozoa (oriented and non-oriented) were sorted into a single tube. Extended spermatozoa were incubated in the dark with
Hoechst $33342\left(0.3 \mu \mathrm{M} / 1 \times 10^{6}\right.$ spermatozoa $)$ for $1 \mathrm{~h}$ at $35{ }^{\circ} \mathrm{C}$. After incubation, samples were filtered through a $30 \mu \mathrm{m}$ nylon mesh filter to remove debris or clumped spermatozoa. These spermatozoa were sorted using an EPICS Altra high speed flow sorter (Beckman Coulter Corporation, Miami, FL, USA) operating at 42 p.s.i. and modified as described by Johnson \& Pinkel (1986) with a Model 90C-6, 6 Q argon laser operated in u.v. light $(351,364 \mathrm{~nm})$ at $175 \mathrm{~mW}$ (Coherent Lasers, Inc., Santa Clara, CA, USA). Flow cytometrically sorted spermatozoa (FCS sperm) were collected in $50 \mathrm{ml}$ bovine serum albumin (BSA)-coated plastic tubes containing $5 \mathrm{ml}$ TEST-yolk (218 mmol TES, $56.1 \mathrm{mmol}$ TRIS, $33.2 \mathrm{mmol}$ glucose and $2 \% \mathrm{v} / \mathrm{v}$ of fresh egg yolk) extender (Johnson et al. 1989) and 10\% boar seminal plasma. FCS sperm were stored at $22{ }^{\circ} \mathrm{C}$ until they were used. Spermatozoa were transferred to $10 \mathrm{ml}$ BSAcoated tubes and concentrated by centrifugation at $500 \mathrm{~g}$ for $4 \mathrm{~min}$ to 150 million spermatozoa in $7.5 \mathrm{ml}$. Only samples showing more than $65 \%$ motility and $70 \%$ intact acrosomes after sorting were used for insemination.

\section{Artificial insemination}

Al was carried out, depending on the experiment, intracervically using an Al catheter (Minitüb Tiefenbach, Germany) or into the depth of one uterine horn using the deep intrauterine insemination technique (DUI) (Martinez et al. 2002).

Standard Al into the cervix was performed in sows with spontaneous ovulation. Detection of oestrus was performed twice per day, beginning 3 days after weaning, by allowing females nose-to-nose contact with a mature boar and by applying back pressure. Sows that exhibited a standing heat reflex were considered to be in oestrus and inseminated. Al into the cervix was performed twice, at 0 and $24 \mathrm{~h}$ after the onset of standing heat.

Since the membranes of FCS spermatozoa may be compromised, we considered that it would be advantageous to induce ovulation in conjunction with the use of DUI. Oestrus was induced by injection of each female intramuscularly with $1250 \mathrm{IU}$ equine chorionic gonadotrophin (Folligon; Intervet International BV, Boxmeer, The Netherlands) $24 \mathrm{~h}$ after weaning followed $72 \mathrm{~h}$ later with $750 \mathrm{IU}$ human chorionic gonadotrophin (hCG) (Chorulon; Intervet International BV). DUI was performed in each sow in gestation crates without sedation, $38 \mathrm{~h}$ after hCG administration. After thorough cleaning of the perineal area of the sow, a commercial $\mathrm{Al}$ catheter was inserted through the vagina into the cervix and used to manipulate a specially designed flexible catheter (working length $1.80 \mathrm{~cm}$, outer diameter $4 \mathrm{~mm}$, diameter of the inner tubing $1.80 \mathrm{~mm}$ ). The flexible catheter was inserted through the spirette, moved through the cervical canal and propelled forward along one uterine horn until all of its length had been inserted. Before insemination the inner tubing of the flexible catheter was rinsed with BTS and refilled with approximately $2 \mathrm{ml}$ BTS at $22^{\circ} \mathrm{C}$. Insemination doses at $22^{\circ} \mathrm{C}$ were flushed into one uterine horn using a $10 \mathrm{ml}$ 
disposable syringe attached to the inner tubing of the flexible catheter. An extra $2 \mathrm{ml}$ BTS alone was then used to force all remaining spermatozoa out of the flexible catheter and into the uterine horn.

\section{Evaluation of reproductive parameters}

Pregnancy was diagnosed at 24-28 days after Al and 15 days later by transcutaneous ultrasonography (Pie Medical, Maastricht, The Netherlands). All pregnant animals were allowed to go to term. Farrowing rates and litter sizes were registered.

\section{Evaluation of the normality of offspring}

\section{Phenotypic evaluation}

Numbers of live, dead, mummified and morphologically abnormal piglets were registered in all litters. All piglets born live were weighed within $2 \mathrm{~h}$ after birth. Each pig was subjected to a daily health inspection during the first 15 days, and the following conditions were noted: ability to stand, unusual discharges from the mouth, bowels, urethra or vagina, eyes or nose. All piglets were weaned at 21 days of age. Weights at 21, 42 and 92 days were registered.

\section{Cytogenetic evaluation}

SCEs and structural CAs were used as biomarkers for the evaluation of DNA damage of lymphocytes of piglets born after insemination of the sows with stained or stained and sorted spermatozoa.

Peripheral blood was aseptically collected from piglets between 3 and 4 months of age (approximately $40-50 \mathrm{~kg}$ weight). Cell suspensions were cultured following the protocol described for goat metaphases by Di Berardino et al. (1996) with minor modifications. Briefly, aliquots of $0.5 \mathrm{ml}$ whole blood containing $6 \times 10^{6}$ lymphocytes were added to each culture flasks containing $8 \mathrm{ml}$ RPMI 1640 medium without L-glutamine (Gibco Life Technologies, Barcelona, Spain), including $1 \mathrm{ml}$ fetal bovine serum, $0.1 \mathrm{ml}$ L-glutamine (Gibco), $50 \mu \mathrm{l}$ antibiotic/antimycotic solution and $0.1 \mathrm{ml}$ Pokeweed mitogen (lectin from Phytolacca americana) to stimulate mitogenetic activity. All cultures were allowed to grow for $68 \mathrm{~h}$ at $38.5^{\circ} \mathrm{C}$. After $48 \mathrm{~h}$ from initiation, $0.1 \mu \mathrm{g} / \mathrm{ml}$ bromodeoxyuridine (BrdU) was added to each culture flask. This concentration of BrdU was the optimal dose obtained in a preliminary study to determine a concentration of BrdU sufficient for sister chromatid differentiation and yet having a minimal effect in the baseline frequencies of SCEs (I Parrilla, J M Vazquez, C Cuello, M A Gil, J Roca, D Di Berardino \& E A Martinez, unpublished observations). Cultures without $\mathrm{BrdU}$ were included in order to analyse the frequencies of CAs.

The cultures were protected from the light and allowed to grow for an additional $20-22 \mathrm{~h}$ at $38.5^{\circ} \mathrm{C}$. Colcemid (Gibco) at $0.1 \mu \mathrm{g} / \mathrm{ml}$ final concentration was added for the final $15 \mathrm{~min}$ prior to harvesting. Harvested cells were collected by centrifugation $(370 \mathrm{~g} / / 10 \mathrm{~min})$, subjected to hypotonic solution $(75 \mathrm{mM} \mathrm{KCl})$ for $20 \mathrm{~min}$ and fixed in methanol/acetic acid $(3: 1 ; \mathrm{v} / \mathrm{v})$. After fixation, the metaphases were dropped onto clean microscope slides and air dried. Air-dried slides were stained with acridine orange at $0.1 \%(\mathrm{w} / \mathrm{v})$ in phosphate buffer $(\mathrm{pH} 7)$ and sealed with paraffin. Samples were examined under a fluorescence microscope (Leica DMRB Fluo; Heerbrugg, Switzerland) and metaphases were stored by digital photography. SCE and CA data were obtained from the analysis of 50 well-spread metaphases in the second division bearing 38 chromosomes (total number of chromosomes in pig cells) and randomly scored per sample. SCE was counted each time that two adjacent segments of one of the chromatids in a chromosome were stained differently and CA was counted each time that a discontinuity or displacement greater that the width of the chromatid arm in one or both of the chromatids was observed. To avoid possible individual bias, all scoring was performed by the same investigator.

\section{Experimental design}

In experiment 1, the genotoxic effect of the Hoechst 33342 staining on boar spermatozoa was evaluated. A total of 45 and 44 sows were intracervically inseminated with $3 \times 10^{9}$ unstained (control) and Hoechst 33342stained spermatozoa respectively in a volume of $80 \mathrm{ml}$. Evaluation of reproductive parameters and piglet phenotypic characteristics was carried out in all sows inseminated and all piglets born respectively. Cytogenetic analysis was performed in eight randomly selected piglets born after insemination with unstained spermatozoa (four piglets, two males and two females) and stained spermatozoa (four piglets, two males and two females).

In experiment 2, the genotoxic effect of the Hoechst 33342 staining followed by the u.v. laser impact on sorted boar spermatozoa was evaluated. A total of 30 and 28 sows with induced ovulation were deeply inseminated with $150 \times 10^{6}$ stained and sorted or unstained and unsorted (control) spermatozoa respectively in a volume of $7.5 \mathrm{ml}$. Evaluation of reproductive parameters and piglet phenotypic characteristics was carried out in all sows inseminated and all piglets born respectively. Cytogenetic analysis was performed in eight randomly selected piglets born after insemination with unstained spermatozoa (four piglets, two males and two females) and stained and sorted spermatozoa (four piglets, two males and two females) respectively.

\section{Statistical analysis}

Data are expressed as percentages or means \pm S.E.M. and differences were considered to be significant at $P<0.05$. The percentage of sows within each insemination group for pregnancy and farrowing rates was compared using a chi-square test with Yate's correction. Litter size, live, low viability, splay leg, mummified piglets and SCE and CA differences were analysed using the GLM procedure 
(ANOVA) of SPSS 11.5/PC statistics package (SPSS Inc., Chicago, IL, USA).

\section{Results}

\section{Experiment 1: evaluation of the genotoxic effect of Hoechst 33342 on boar spermatozoa}

The data shown are from 8 consecutive weeks. Reproductive parameters for the inseminations performed in this experiment are shown in Table 1. Pregnancy rates, farrowing rates and litter size did not significantly differ $(P>0.05)$ from the control group when Hoechst 33342stained spermatozoa were used for Al.

There was no difference in the number of piglets born alive $(9.97 \pm 3.20$ vs $9.97 \pm 2.72)$, low viability piglets $(0.39 \pm 0.63$ vs $0.51 \pm 0.83)$, mummified piglets $(0.21 \pm 0.41$ vs $0.27 \pm 0.45)$ and in the number of piglets suffering from splay leg $(0.28 \pm 0.51$ vs $0.35 \pm 0.78$ ) for piglets born after insemination with unstained and Hoechst 33342-stained spermatozoa respectively $(P>0.05)$.

Birth weight and 21-day weaning weight means for piglets born with stained spermatozoa were established at about $1.48 \pm 0.04$ and $5.65 \pm 0.2 \mathrm{~kg}$ respectively, and no significant variations $(P>0.05)$ with respect to the control group $(1.36 \pm 0.03 \mathrm{~kg}$ at the day of birth and $5.72 \pm 0.3 \mathrm{~kg}$ at 21 days of weaning) were observed. Similar results were found at 42 and 92 days with weight means of $10.21 \pm 0.6$ and $47.50 \pm 1.3$ and $10.18 \pm 0.7$ and $47.23 \pm 1.5$ for piglets born from unstained and Hoechst 33342-stained spermatozoa.

An average rate of $3.1 \pm 0.21$ SCEs/metaphase and $2.8 \pm 0.16 \mathrm{SCEs} / \mathrm{metaphase}$ was found in lymphocytes from piglets born after insemination with unstained (control) and Hoechst 33342-stained spermatozoa respectively. This small difference was within the range of biological variability and did not reach statistical significance $(P>0.05)$ (Table 2). Differences in SCE frequencies within piglets in the same group were observed but these differences did not reach statistical significance $(P>0.05)$. No interaction $(P>0.05)$ between the sex of the piglets and the number of SCEs per cell was observed.

CAs in metaphase analyse of lymphocytes revealed mainly chromatid breaks. Percentages of metaphases with CAs (in one or two chromatids) were low, ranging from an average rate of $0.05 \pm 0.01$ CAs/metaphase and $0.04 \pm 0.01 \mathrm{CAs} / \mathrm{metaphase}$ for control and Hoechst

Table 1 Pregnancy rates, farrowing rates and litter size in sows inseminated with $3 \times 10^{9}$ Hoechst 33342-stained or unstained (control) spermatozoa. Value for litter size are means \pm S.E.M

\begin{tabular}{lcccc}
\hline $\begin{array}{l}\text { Treatment } \\
\text { group }\end{array}$ & $\begin{array}{c}\text { No. of sows } \\
\text { inseminated }\end{array}$ & $\begin{array}{c}\text { Pregnancy } \\
\text { rates }(\%)\end{array}$ & $\begin{array}{c}\text { Farrowing } \\
\text { rates }(\%)\end{array}$ & $\begin{array}{c}\text { Litter } \\
\text { size }(n)\end{array}$ \\
\hline Stained & 44 & 86.3 & 84.0 & $10.8 \pm 2.9$ \\
Unstained & 45 & 84.4 & 82.2 & $11.1 \pm 2.3$ \\
\hline
\end{tabular}

Reproduction (2004) 128 615-621
Table 2 Mean \pm S.E.M. rates of SCEs and CAs per cell in the lymphocytes of piglets born after insemination with $3 \times 10^{9}$ Hoechst 33342-stained or unstained (control) spermatozoa. Each entry is the mean \pm S.E.M. for 50 metaphase cells.

\begin{tabular}{llllc}
\hline Donor & Group & Sex & SCEs & CAs \\
\hline 1 & Control & Male & $3.38 \pm 0.37$ & $0.12 \pm 0.05$ \\
2 & Control & Male & $2.72 \pm 0.27$ & $0.04 \pm 0.03$ \\
3 & Control & Female & $2.92 \pm 0.28$ & $0.02 \pm 0.02$ \\
4 & Control & Female & $3.48 \pm 0.45$ & $0.04 \pm 0.03$ \\
5 & Stained & Male & $2.40 \pm 0.31$ & $0.16 \pm 0.05$ \\
6 & Stained & Male & $3.08 \pm 0.53$ & $0.02 \pm 0.02$ \\
7 & Stained & Female & $3.12 \pm 0.36$ & $0.01 \pm 0.01$ \\
8 & Stained & Female & $2.60 \pm 0.35$ & $0.00 \pm 0.00$ \\
Mean & Control & & $3.12 \pm 0.21$ & $0.05 \pm 0.01$ \\
Mean & Stained & & $2.80 \pm 0.16$ & $0.04 \pm 0.01$ \\
\hline
\end{tabular}

33342-stained spermatozoa respectively. The sex of the piglets did not affect the CA frequencies $(P>0.05)$.

\section{Experiment 2: evaluation of the genotoxic effect of Hoechst 33342 followed by the u.v. laser impact on sorted boar spermatozoa}

The data shown are from 15 consecutive weeks. Reproductive parameters for the deep intrauterine inseminations performed in this experiment are shown in Table 3. Significantly lower pregnancy and farrowing rates and litter size were seen using FCS spermatozoa when compared with control spermatozoa $(P<0.05)$.

No variations for low viability piglets $(0.25 \pm 0.33$ vs $0.42 \pm 0.51)$, mummified piglets $(0.14 \pm 0.34$ vs 0.19 $\pm 0.32)$ and in the number of piglets suffering splay leg $(0.34 \pm 0.43$ vs $0.43 \pm 0.65)$ were found between piglets in the control group and those obtained after DUI inseminations with stained and sorted spermatozoa respectively.

Birth weight and 21-day weaning weight means for piglets born in the control group were established at about $1.46 \pm 0.03 \mathrm{~kg}$ and $5.65 \pm 0.4 \mathrm{~kg}$ respectively, and no significant variations $(P>0.05)$ with respect to the piglets born after inseminations with FCS spermatozoa (1.52 \pm $0.03 \mathrm{~kg}$ at the day of birth and $5.72 \pm 0.2 \mathrm{~kg}$ at 21 days of weaning) were observed. Similar results were found at 42 and 92 days with weight means of $10.89 \pm 0.5$ and $48.12 \pm 1.6$ and $10.57 \pm 0.8$ and $47.59 \pm 1.2$ for piglets born from control and FCS spermatozoa.

Table 3 Pregnancy rates, farrowing rates and litter size in sows inseminated with $150 \times 10^{6}$ of FCS or unstained and unsorted (control) spermatozoa. Values for litter size are means \pm S.E.M.

\begin{tabular}{lcccc}
\hline $\begin{array}{l}\text { Treatment } \\
\text { group }\end{array}$ & $\begin{array}{c}\text { No. of sows } \\
\text { inseminated }\end{array}$ & $\begin{array}{c}\text { Pregnancy } \\
\text { rates }(\%)\end{array}$ & $\begin{array}{c}\text { Farrowing } \\
\text { rates }(\%)\end{array}$ & $\begin{array}{c}\text { Litter } \\
\text { size }(n)\end{array}$ \\
\hline FCS & 30 & $43.3^{\mathrm{a}}$ & $36.6^{\mathrm{a}}$ & $8.1 \pm 1.9^{\mathrm{a}}$ \\
Control & 28 & $89.2^{\mathrm{b}}$ & $82.1^{\mathrm{b}}$ & $10.9 \pm 1.6^{\mathrm{b}}$
\end{tabular}

Values within columns with different superscripts are significantly different $(P<0.05)$. 
An average rate of $2.6 \pm 0.19 \mathrm{SCEs} /$ metaphase and $2.6 \pm 0.26 \mathrm{SCEs} / \mathrm{metaphase}$ was found in lymphocytes from piglets born after insemination with control and FCS spermatozoa respectively. As occurred in experiment 1, a small difference was found within the range of biological variability and did not reach statistical significance $(P>0.05)$ (Table 4).

CAs in metaphase analyse of lymphocytes also revealed mainly chromatid breaks. Percentages of metaphases with CAs (in one or two chromatids) were low, ranging from an average rate of $0.05 \pm 0.01 \mathrm{CAs} /$ metaphase and $0.06 \pm 0.02 \mathrm{CAs} /$ metaphase for control and FCS spermatozoa respectively.

No significant variations $(P>0.05)$ were found in SCE and CA frequencies between males and females.

\section{Discussion}

Considerable reservations concerning the genetic safety of a process that involves Hoechst 33342 spermatozoa staining in combination with u.v. laser impact have been expressed by some authors (Ashwood-Smith 1994, Munné 1994), especially after the successful application of this technology to the separation of human spermatozoa (Johnson et al. 1993). It is well known that both Hoechst 33342 and u.v. laser are toxic and/or mutagenic when used in somatic cells (Durand \& Olive 1982, Sinha \& Hader 2002). However, to the best of our knowledge, no data concerning the mutagenic effects of these agents on boar spermatozoa as required for preselecting the sex by the flow cytometry sorting procedure are available.

We evaluated two steps of the flow cytometric sorting procedure that could be potentially harmful to the functional and chromosomal integrity of spermatozoa. First, the individual effect of the Hoechst 33342 on the spermatozoa and, secondly, the additive effect of the u.v. laser irradiation on the Hoechst 33342-stained spermatozoa.

The dosage of Hoechst 33342 required for staining spermatozoa before sorting by sexual chromosome did not affect pregnancy rates at 24-28 days and either farrowing rates or litter size. These findings are not compatible with

Table 4 Mean \pm S.E.M. rates of SCEs and CAs per cell in the lymphocytes of piglets born after insemination with $150 \times 10^{6}$ FCS spermatozoa or unstained and unsorted (control) spermatozoa. Each entry is the mean \pm S.E.M. for 50 metaphase cells.

\begin{tabular}{llllc}
\hline Donor & Group & Sex & SCEs & CAs \\
\hline 1 & Control & Male & $2.34 \pm 0.25$ & $0.05 \pm 0.04$ \\
2 & Control & Male & $2.65 \pm 0.31$ & $0.03 \pm 0.03$ \\
3 & Control & Female & $2.41 \pm 0.37$ & $0.09 \pm 0.05$ \\
4 & Control & Female & $3.23 \pm 0.41$ & $0.04 \pm 0.03$ \\
5 & FCS & Male & $2.36 \pm 0.27$ & $0.04 \pm 0.04$ \\
6 & FCS & Male & $2.46 \pm 0.34$ & $0.06 \pm 0.03$ \\
7 & FCS & Female & $3.16 \pm 0.32$ & $0.10 \pm 0.05$ \\
8 & FCS & Female & $2.44 \pm 0.37$ & $0.04 \pm 0.03$ \\
Mean & Control & & $2.65 \pm 0.19$ & $0.05 \pm 0.01$ \\
Mean & FCS & & $2.60 \pm 0.26$ & $0.06 \pm 0.01$ \\
\hline
\end{tabular}

damage to the sperm chromatin integrity because it has been demonstrated that when the chromatin is compromised, failures in fertilization, early embryonic losses and spontaneous abortions are observed (Evenson 1999). This innocuous effect of Hoechst 33342 on boar spermatozoa under our experimental conditions is in agreement with those obtained earlier (Vazquez et al. 2002). In the same way, piglets obtained after Al with Hoechst 33342-stained spermatozoa appeared to be no different from controls, either in the presence of congenital abnormalities or their growth at 21, 42 and 92 days, reinforcing the apparent innocuous effect of Hoechst 33342 on boar spermatozoa.

As far as we know, no data on cytogenetic analysis in piglets born from Hoechst 33342-stained spermatozoa have previously been reported. Genotoxicity endpoints, such as SCEs and CAs, are widely used as biomarkers of exposure to DNA-damaging agents. SCE evaluation is considered to be a more sensitive cytogenetic method than CA for evaluating genotoxic potential of a variety of mutagenic and carcinogenic agents (WHO 1993). However, one cytogenetic analysis alone is not generally accepted as sufficient evidence to classify an agent as mutagenic (WHO 1985). Thus, taking into account that the two genetic endpoints used here are not mutually exclusive but complementary and that they can respond with different sensitivities to the suspect agent, they have been included in the present study.

No significant increase in baseline frequencies of SCEs/cell and CAs/cell was found in lymphocytes from piglets born after insemination with Hoechst 33342-stained spermatozoa compared with lymphocytes of animals from the control group. These findings suggested that Hoechst 33342 does not induce DNA damage; this was expected since this DNA-specific dye has been defined as a nonintercalating agent and binds to the minor groove of the adenine-thymine regions of the DNA helix (Johnson \& Schulman 1994). In addition, the extreme degree of condensation of DNA in the sperm by substitution of histones by protamines increases its protection against foreign influences (Tanphaichtr et al. 1978, Rodriguez-Martinez et al. 1990).

Variations in the number of SCEs/cell among individuals within the same group, regardless of sex, were found but not at significant levels. This slight variation can be mainly attributed in our experiment to the concentration of $\mathrm{BrdU}$ relative to the number of lymphocytes in the culture which is an individual factor (Carrano et al. 1980). Since the presence of $\mathrm{BrdU}$ in the culture medium is necessary to achieve chromatid differentiation for disclosure of the exchanges, $0.1 \mu \mathrm{g} / \mathrm{ml}$ was found to be the limit in our experimental conditions for discriminating sister chromatid differential staining as observed earlier for several ruminant species (Di Berardino et al. 1996, 1997).

On the other hand, when Hoechst 33342-stained spermatozoa were passed through the u.v. laser beam of the flow cytometer, pregnancy rates, farrowing rates and litter size obtained after DUI insemination were significantly 
lower than those obtained for the control group (unstained and unsorted spermatozoa). It is well known that the fertile life span of spermatozoa is considerably reduced by flow cytometric sorting (Vazquez et al. 2003). However, the reason for this reduction remains unclear and no in-depth explanation has yet been given. The exposure of the Hoechst 33342-stained spermatozoa to the laser and/or the passage of the spermatozoa through the flow cytometer (including the high dilution rate, the projection into the collection tube or the post-sort centrifugation required for in vitro or in vivo insemination) are highlighted as the two main sources of the loss of reproductive yield. If the damage were more related to DNA changes, the fall in the reproductive parameters should be associated with an increased rate of abortions or congenital abnormalities as well as with an increase of SCEs and CAs in the piglets. By contrast, if the damage was more related to alterations in the functionality of spermatozoa shortening the fertile life span of the cells, a decrease in the reproductive index alone, without other associated alterations, would be expected.

It could be argued that the u.v. laser beam may be having an impact on some of the spermatozoa because u.v. radiation induces two of the most abundant mutagenic and cytotoxic DNA lesions in somatic cells (Sinha \& Hader 2002). In addition, a reduction in the development of embryos has been observed after inseminating flow-sorted spermatozoa in pigs (Johnson 1991), rabbits (McNutt \& Johnson 1996) and cows (Cran et al. 1993). DNA-damaged spermatozoa can fertilize oocytes at the same rate as intact DNA sperm but embryonic development is significantly decreased (Ahmadi \& Ng 1999). However, more recent studies undertaken with bovine or porcine zygotes showed that sorting stained spermatozoa with the new high speed flow sorter did not affect embryo development in blastocysts (Guthrie et al. 2002, Zhang et al. 2003). We must take account that if the u.v. laser has any effect, the duration of exposure of the stained sperm to u.v. laser light using the current high speed sperm-sorting procedure is much shorter than the exposure time necessary when standard speed flow-sorting cytometers are used. Consequently any presumed u.v. damage to spermatozoa would be expected to be less with this shorter u.v. light exposure (Guthrie et al. 2002). In addition, it is also important to note that the high degree of condensation of the sperm chromatin, in comparison with other cells, makes DNA highly resistant to physical or chemical agents (Lopes et al. 1998), and thus could represent an optimal protection from u.v. laser impact. Moreover, the safety of the procedure is reinforced by phenotypic and cytogenetic analysis done in our experiments. The normalcy of piglets obtained from our experiment as well as in earlier studies (Johnson 1991, Rath et al. 1997, 1999, Abeydeera et al. 1998, Vazquez et al. 2003) allows us to deduce that no severe DNA damage resulting from the combination of staining and laser beam is induced in boar spermatozoa and thus no genetic abnormalities are expected in the offspring. Moreover, no deviations from SCE and CA baseline frequencies were found for these piglets with respect to the control group.

On the other hand, it could also be argued that the sorting process itself could induce alterations in membrane status, changes in motility patterns, thereby reducing the fertile life span of the spermatozoa regardless of the Hoechst 33342 staining or u.v. laser impact effect (Johnson 1995, Maxwell et al. 1997, Maxwell \& Johnson 1999, Parrilla et al. 2001). In truth, a reduction in the fertility index without any increase in lost pregnancies, abortions or morphological abnormalities should be obtained as observed in our experiments where, in addition, the cytogenetic analysis did not shown any deviations from baseline levels according to the phenotypical normalcy of the offspring.

In conclusion, this is the first report confirming the absence of in vivo genotoxic effects of the flow cytometrysorted semen technology, based not only on the lack of phenotypic evidence but also on the absence of increases in the frequencies of mutagenic indexes in the offspring. Further analyses on specific genes in boar spermatozoa should be undertaken to increase our knowledge about of the genetic safety of this procedure.

\section{Acknowledgements}

We are grateful to $\mathrm{W} \vee$ Holt for helpful suggestions and critical reading of the manuscript and to J Tornel and I Burguete for their excellent assistance and help. This study was supported by grants from EUREKA (EU-1713), CDTI (03-0402/0180), Fundación Seneca (PB/74/FS/02) and Direccion General de Ciencia y Tecnologia y Sociedad de la Información de la Region de Murcia (2002/30.476).

\section{References}

Abeydeera LR, Johnson LA, Welch GR, Wang WH, Boquest AC, Cantley TC, Rieke A \& Day BN 1998 Birth of piglets preselected for gender following in vitro fertilization of in vitro matured pig oocytes by $\mathrm{X}$ - and Y-chromosome bearing spermatozoa sorted by high speed flow cytometry. Theriogenology 50 981-988.

Ahmadi A \& Ng SC 1999 Fertilizing ability of DNA-damaged spermatozoa. Journal of Experimental Zoology 284 696-704.

Albertini RJ, Anderson D, Douglas GR, Hagmar L, Hemminki K, Merlo F, Natarajan AT, Norppa H, Shoker DE, Tice R, Waters MD \& Aitio A 2000 IPCS guidelines for the monitoring of genotoxic effects of carcinogens in humans. International programme on chemical safety. Mutation Research 463 111-172.

Ashwood-Smith MJ 1994 Safety of human sperm selection by flow cytometry. Human Reproduction 9757.

Carrano AV \& Natarajan AT 1988 Considerations for population monitoring using cytogenetic techniques. International Commission for protection against environmental mutagens and carcinogens. Mutation Research 204 379-406.

Carrano AV, Minkler JL, Stetka DG \& Moore DH 1980 Variation in the baseline sister chromatid exchange frequency in human lymphocytes. Environmental Mutagenesis 2 325-337.

Cran DG, Johnson LA, Miller NG, Cochrane D \& Polge C 1993 Production of bovine calves following separation of $\mathrm{X}$ - and 
Y-chromosome bearing sperm and in vitro fertilisation. Veterinary Record 132 40-41.

Di Berardino D, Jovino V, Lioi MB, Scarfi MR \& Burguete I 1996 Spontaneous rate of sister chromatid exchanges (SCEs) and BrdU dose-response relationships in mitotic chromosomes of goat (Capra hircus L.). Hereditas 124 137-143.

Di Berardino D, Ramunno L, Jovino V, Pacelli C, Lioi MB, Scarfi MR \& Burguete I 1997 Spontaneous rate of sister chromatid exchanges (SCEs) in mitotic chromosomes of sheep (Ovis aries L.) and comparision with cattle (Bos taurus L.), goat (Capra hircus L.) and river buffalo (Bubalus bubalis L.). Hereditas 127 231-238.

Durand RE \& Olive PL 1982 Cytotoxicity, mutagenicity and DNA damage by Hoechst 33342. Journal of Histochemistry and Cytochemistry $30111-116$.

Evenson DP 1999 Loss of livestock breeding efficiency due to uncompensable sperm nuclear defects. Reproduction, Fertility and Development 11 1-15.

Gardiner-Garden M 1999 Technique for sorting X and Y spermatozoa may adversely affect histone-associated regions in human spermatozoa. Human Reproduction 14 1403-1404.

Guthrie HD, Johnson LA, Garret WM, Welch GR \& Dobrinsky JR 2002 Flow cytometric sperm sorting: effects of varying laser power on embryo development in swine. Molecular Reproduction and Development 61 87-92.

Johnson LA 1991 Sex preselection in swine: altered sex ratios in offspring following surgical insemination of flow sorted $X$ or Y-bearing sperm. Reproduction in Domestic Animals 26 309-314.

Johnson LA 1995 Separation of $X$ and $Y$ chromosome bearing sperm based on DNA differences. Reproduction, Fertility and Development 7 893-903.

Johnson LA 2000 Sexing mammalian sperm for production of offspring: the state-of-the-art. Animal Reproduction Science 60-61 93-107.

Johnson LA \& Pinkel D 1986 Modification of a laser-based flow cytometer for high resolution DNA analysis of mammalian spermatozoa. Cytometry 7 268-273.

Johnson LA \& Schulman JD 1994 The safety of sperm selection by flow cytometry. Human Reproduction 9 758-759.

Johnson LA \& Welch GR 1999 Sex preselection: high-speed flow cytometry sorting of $\mathrm{X}$ and $\mathrm{Y}$ sperm for maximum efficiency. Theriogenology 52 1323-1341.

Johnson LA, Aalbers JG \& Grooten HJG 1988 Artificial insemination of swine: fecundity of boar semen stored in Beltsville TS (BTS), modified modena (MM) or MR-A and inseminated on one, three and four days after collection. Zuchthygiene 23 49-55.

Johnson LA, Flook JP \& Hawk HW 1989 Sex preselection in rabbits: live births from X-and Y-sperm separated by DNA and cell sorting. Biology of Reproduction 41 199-203.

Johnson LA, Welch GR, Keyvanfar K, Dorfman K, Fugger EF \& Schulman JD 1993 Gender preselection in humans? Flow cytometric separation of $X$ and $Y$ spermatozoa for the prevention of $X$-linked diseases. Human Reproduction 8 1733-1739.

Latt SA, Allen J, Bloom SE, Carrano A, Falke E, Kram D, Schneider E, Schreck R, Tice R, Whitefield B \& Wolff S 1981 Sister chromatid exchanges: a report of the Gene-Tox program. Mutation Research 87 17-62.

Lopes S, Jurisicova A, Sun JG \& Casper RF 1998 Reactive oxygen species: potential cause for DNA fragmentation in human spermatozoa. Human Reproduction 13 896-900.

McNutt TL \& Johnson LA 1996 Flow cytometric sorting of sperm: influence on fertilization and embryo/fetal development in the rabbit. Molecular Reproduction and Development 43 261-267.

Martinez EA, Vazquez JM, Roca J, Lucas X, Gil MA, Parrilla I, Vazquez JL \& Day BN 2002 Minimal number of spermatozoa required for normal fertility after deep intrauterine insemination in non-sedated sows. Reproduction 123 163-170.

Matsuda Y \& Tobari I 1988 Chromosomal analysis in mouse eggs fertilized in vitro with sperm exposed to ultraviolet light (UV) and methyl and ethyl methanesulfonate (MMS and EMS). Mutation Research 198 131-144.

Maxwell WMC \& Johnson LA 1999 Physiology of spermatozoa at high dilution rates: the influence of seminal plasma. Theriogenology 52 1353-1362.

Maxwell WMC, Welch GR \& Johnson LA 1997 Viability and membrane integrity of spermatozoa after dilution and flow cytometric sorting in the presence or absence of seminal plasma. Molecular Reproduction and Development 8 1165-1178.

Morrel JM \& Dresser DW 1989 Offspring from insemination with mammalian sperm stained with Hoechst 33342, either with or without flow cytometry. Mutation Research 224 177-189.

Munné S 1994 Flow cytometry separation of X and Y spermatozoa could be detrimental for human embryos. Human Reproduction 9 758.

Parrilla I, Vazquez JM, Centurion F, Roca J, Gil MA, Lucas X \& Martinez EA 2001 Effect of high-speed flow sorting on sperm motility pattern of boar sperm. Theriogenology 55501 (Abstract).

Perry P \& Evans HJ 1975 Cytological detection of mutagen-carcinogen exposure by sister chromatid exchanges. Nature 258 $121-125$.

Rath D, Johnson LA, Dobrinsky JR, Welch GR \& Niemman H 1997 Production of piglets preselected for sex following in vitro fertilization with $\mathrm{X}$ and $\mathrm{Y}$ chromosome-bearing spermatozoa sorted by flow cytometry. Theriogenology 47 795-800.

Rath D, Long CR, Dobrinsky JR, Schreier LL, Welch GR \& Johnson LA 1999 In vitro production of sexed embryos for gender preselection: high speed sorting of X-chromosome bearing sperm to produce piglets after embryo transfer. Journal of Animal Science $773346-3352$.

Rodriguez-Martinez H, Courtens JL, Kvist U \& Ploen L 1990 Immunocytochemical localization of nuclear protamine in boar spermatozoa during epididymal transit. Journal of Reproduction and Fertility $89591-595$.

Sinha RP \& Hader DP 2002 UV-induced damage and repair: a review. Photochemistry and Photobiology 1 225-236.

Tanphaichtr N, Sobhon P, Taluppte N \& Chalermisarachi P 1978 Basic nuclear proteins in testicular cells and ejaculated spermatozoa in man. Experimental Cell Research 117 347-356.

Vazquez JM, Martinez EA, Martinez P, Garcia-Artiga C \& Roca J 1997 Hypoosmotic swelling of boar spermatozoa compared to other methods for analysing the sperm membrane. Theriogenology 47 913-922.

Vazquez JM, Martinez EA, Parrilla I, Gil MA, Lucas X \& Roca J 2002 Motility characteristics and fertilizing capacity of boar spermatozoa stained with Hoechst 33342. Reproduction in Domestic Animals 37 369-374.

Vazquez JM, Martinez EA, Parrilla I, Roca J, Gil MA \& Vazquez JL 2003 Birth of piglets after deep intrauterine insemination with flow cytometrically sorted boar spermatozoa. Theriogenology $\mathbf{5 9}$ $1605-1614$.

WHO 1985 IPCS Environmental Health Criteria 51: Guide to Shortterm Test for Detecting Mutagenic and Carcinogenic Chemicals, Geneva: World Health Organization.

WHO 1993 IPCS Environmental Health Criteria 155: Biomarkers and Risk Assessment: Concept and Principles, Geneva: World Health Organization.

Zhang M, Lu KH \& Seidel GE Jr 2003 Development of bovine embryos after in vitro fertilization of oocytes with flow cytometrically sorted, stained and unsorted sperm from different bulls. Theriogenology $601657-1663$.

Received 23 April 2004

First decision 13 July 2004

Accepted 20 July 2004 